\title{
Development of Ecological Process Dry Cleaning to Wash Alpaca Fiber Garments
}

\author{
Zegarra A., Member, IACSIT
}

\begin{abstract}
This document shows the results of developed a dry cleaning process that replaces the traditional dry cleaning using perchlorethylene solvent, which we know is highly damaging to people and the environment.

This process has several components on which we have worked to get to determine an alternate method of dry cleaning with new ecological solvent, washing the results through testing quality textiles which have been washed garments under this new process give an even better positive results of the current market and this procedure is considered as the best alternative to dry cleaning Alpaca fiber reducing gradually the use of traditional process with harmful Perchloroethylene solvent currently employed in Arequipa-Perú city.
\end{abstract}

Index Terms-Dry cleaning process, DF 2000 solvent.

\section{INTRODUCTION}

We must first talk about two very important issues for this research.

\section{A. Water shortage}

Drought causes devastating effects in countries that suffer. Many countries have less water than they need. Early next century, a third of the nations will have water shortages permanently. Spring is becoming poorer as a result of the clearing of forests and climate change instead. Underground lakes, dating from prehistoric times, are being depleted rapidly [1].

Of all the social and natural crises we humans face, the water resource is one that most affects our own survival and that of the planet. No region will be spared from the impact of this crisis that affects all aspects of life, from children's health to feed humans. Water supplies are falling while the demand is growing at an unsustainable rate. It is expected that in the next twenty years the global average water supply per capita will decrease by one third.

Currently, the industry uses $22 \%$ of the water consumed in the world. In rich countries the figure rises to $59 \%$, while in poor countries only reached $8 \%$. In 2025 this will have risen by $24 \%$. It is estimated that by then $1,170 \mathrm{~km}^{3}$ of water will be spent annually for industrial use.

If we talk in the textile sector and specifically in laundries, then that alternative we have, the only answer the dry cleaning, is make washing processes without using water.

Manuscript received January 15, 2014; revised April 2, 2014.

Zegarra A. is with the Energy and Environment Institute, San Pablo Catholic University, Arequipa, Perú (e-mail: azegarrab@ucsp.edu.pe).

\section{B. About Perchloroethylene Solvent [2]}

Perchloroethylene is a manufactured chemical that is mainly used for dry cleaning of textile and metal degreasing. It is also used in the manufacture of other chemicals, including chlorofluorocarbons, and rubber liners, as insulation and refrigerant fluid in electrical transformers, and as a cleaning agent, scrub and desizing of textiles [3].

\section{Negative Effects on People Perchloroethylene}

Perchloroethylene is listed as "reasonably anticipated human carcinogen by" in the Twelfth Report on Carcinogens published by the National Toxicology Program because prolonged exposure to it can cause leukemia and skin cancer, colon, lung, larynx, bladder urinary and genitourinary tract.

Prolonged exposure can also damage the central, liver and kidneys nervous system can also cause respiratory failure, memory loss, confusion, and drying and cracking of the skin. If you are pregnant, prolonged exposure to Perchlorethylene may harm the developing fetus.

The short-term exposure to high levels of Perchlorethylene can cause fluid accumulation in the lungs, eye irritation and airway, severe shortness of breath, sweating, nausea, vomiting, headache, dizziness, drowsiness, confusion and difficulty talk and walk.

The short-term exposure to low levels of perchlorethylene can cause dizziness, intoxication, drowsiness and irritation of the eyes, nose, mouth, throat and respiratory tract. Direct contact with Perchlorethylene in liquid or vapor form can irritate and burn the skin, eyes, nose and throat.

\section{Negative Effects of Environmental Perchloroethylene [4]}

The Perchloroethylene is not very persistent in the air, have a tendency to react photochemical mind when exposed to sunlight and also react with hydroxyl radicals. This degradation can occur in a period between a few hours to a few months, so it is not considered a destructive agent of the ozone layer, but is subject to transport over long distances.

Surface water: Rain washes atmospheric Perchloroethylene to water, but most re-evaporated very quickly and, depending on wind and mixing conditions, the half-life may vary from several hours to several weeks. The Perchloroethylene can enter the biological environment and be metabolized. Many of the degradation products formed in the water PERC are often more persistent (in water) the same Perchloroethylene.

\section{E. Why Dry Cleaning}

First, the process of dry cleaning is an unavoidable requirement of contemporary society by profound shortage of fresh water in the world because the projections of 
consumption of this element versus the quantity available in rivers, lakes, rivers and layers groundwater is alarming, so that new process is being developed that include the use of low water levels.

Secondly, the current process of dry cleaning with solvent Perchloroethylene is already banned in the major markets of the world for being a highly toxic product to be human and environmental contaminant, but in many countries are continuing to indiscriminately using this process lack of control and awareness of the harmful damage caused by this solvent [5].

\section{F. Current Situation}

In Latin America, specifically Perú, the dry cleaning is almost always with the solvent called Perchloroethylene, also known and called as tetrachlorethylene, or PERC

\section{THEORETICAL}

\section{A. Market to Dry Cleaning}

Most people in our country washed all his clothes with conventional processes, is with water and detergents and conventional soaps, this is changing because there is an increasing number of people are beginning to wash your clothes dry processes mainly:

- Longer garments, retaining the look of new.

- If you act quickly, we can remove most stains, however, over time, dirt or spots age, they oxidize and react with the fiber deletion impossible, for that reason there is ever saved or laundry blotchy, or take in cleaning.

- With use, all items require a recycle to keep looking good, clean, odorless, pollution, etc. (dust acts as small crystals that are tearing the fibers. Parasites, moth, etc. do not nest in clean clothes). So use every so often the household washing machine, but the rest of the clothes washed at home should not be dry cleaned for their preservation.

- The cleaning removes dirt and better fats and oil and stains.

- It has adequate professional and technical (knowledge, equipment and specific products).

- Dry cleaning not wearing fabric.

- Dry cleaning not shrink, dry, no wrinkle, regenerates respects and preserves the colors look again.

\section{Benefits to dry wash:}

- Another important benefit offered dry cleaning is that many clothes should be washed under this process, as many fabrics and garments would suffer irreparable harm as a typical shrinkage, discoloration, damage to accessories such as buttons or additions (sequins, ornaments, plastic). In addition to the life of wearing washing increases compared to water, being a benefit to the end user.

- Power consumption is substantially lowered. By not having to heat the solvent for distillation, we saved a lot of Kilowatt in each wash cycle.

- Important savings in consumables (soap, stain removal, reinforcing)

- As the dry process, the use of water is minimal and therefore the emission also drains.

\section{B. About the Solvent Used in the New Ecological Process [6]}

The solvent with which the tests were developed and generated the best results in the process of dry cleaning of clothing Alpaca is DF 2000 (Hydrocarbon) developed by EXXON MOBILE USA.

\section{Benefits of hydrocarbon:}

- It is a solvent free which you can buy from any supplier and manufacturer. It has no patent or royalties.

- It is less volatile than the perchlorethylene, thus save consumption substantially less solvent to evaporate.

- It has more cleaning power than silicones and similar to Perchloroethylene practical effect. Although the rate of cleaning (Kauri Butanol) is smaller than the PERC, the dissolution of the dirt from the clothes to be treated is clean enough to leave, to a level similar to the PERC. Moreover, having a lower kauri butanol, protect more clothes.

- It is not dangerous to human health by inhalation, which is not nearly volatile.

- It is less aggressive than the PERC with the clothes, therefore there are not many discolorations and cares more flair or additions (sequins, ornaments, plastic) that the PERC.

- With the hydrocarbon solves one of the big problems with PERC dry cleaning: odors. With no oil or scent trail left in the store or on the clothes.

\section{About Washing Machine Used to Wash [7]}

The machine, on which the tests were performed in dry cleaning with DF 2000, is the F15 Multisolvent ASTS2 designed and manufactured by the Company Firbimatic in Italy (Fig. 1), with a capacity of 15 kilos or less, and can work with different alternative solvents but not with PERC.

An amount of solvent mixed with water is introduced into the pre-wash cycle hereinafter to enhance removal of water soluble stains and obtain an excellent cleaning washing.
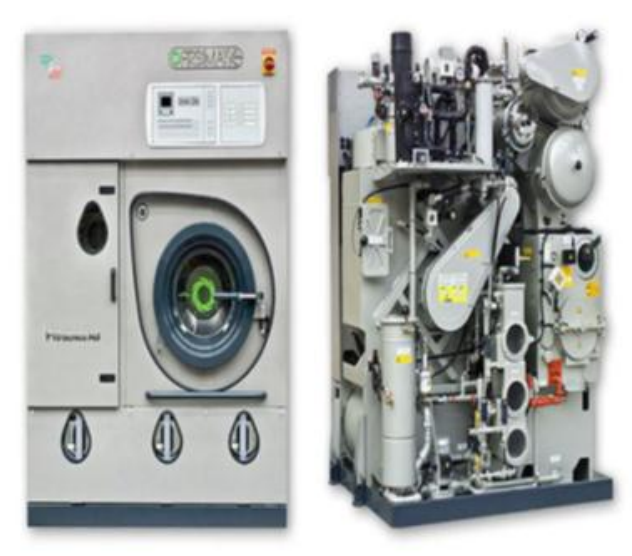

Fig. 1. Multisolvent machine Firbimatic F-15AST2 (Source: Firbimatic Italy).

The garments used for the tests were completely made in Alpaca fiber.

\section{About Fiber Alpaca [8]}

The luxury fiber of the alpaca is one of the main sources of identity wealth that Perú possesses. This animal is distinctly 
Peruvian, inhabits the Andes, and in recent years its fiber has opened one of the most promising markets in textiles. Perceived as a luxury fiber high price, alpaca fiber is one of the most appreciated worldwide. Perú is the largest exporter of this product. This export potential level is being affected by the deterioration of the quality of the fiber that is being offered to the market.

\section{Methodology AND Results}

After a series of tests, analyzes, corrections and improvements which have considered all the technical aspects of the washing machine, the solvent proposed as a replacement of the qualities and characteristics of the items to be washed, the sequence of activities and tasks performed by our technical team, we can assert that the technical impact of the process generates the best results.

\section{A. Garment Inspection Process}

The garment to be washed should be inspected before the washing process in order to identify problems with broken clothes, soiled by oil rectilinear machines which are woven garments, garments non sewn or broken sewn and others to proceed with the spotting or correct classification of items according to the problem they have.

\section{B. Process Pre-Spotting}

There are stains or spots on garments that will hardly be removed by the DF 2000 during the washing process on the machine. By spotting these garments are soaps and active tense specially designed for this work and showing a high degree of compatibility with the used DF 2000. These high performance products that act not only as soap, but also as emulsifiers in the aqueous part, allowing you to add water in the spotting (on clothes that allow it) and enter the laundry in the machine cleaning. Applied by spray or brush depending on location and the intensity of the stain.

The stain removal process is done manually and is a strictly operative position, is achieved by washing the stain promptly with a dose of any of the three products mentioned above.

The dose used varies according to the intensity and depth of the soil and may be between 0.2 to 0.5 grams of product per kilo of garments.

Removed the stain once left to dry the garment environment waiting for the next process.

\section{The Linking Process}

If the laundry items are on panels that is the garment components are separated process over lock thereof is required prior to washing because the movement of the clothes inside the drum of the machine friction forces fiber created - metal and fiber - fiber that causes tearing if you do not have their sewn edges.

It is very important to remove through the manual mending the tears and holes to prevent clothes are bigger and end up making a second pass through the garment and are discarded for sale.

\section{Steaming Process 1}

Alpaca fiber is one of the most sensitive to external factors such as temperature, the fold, handling, storage and friction.
Before washing clothes or Alpaca fiber panels in any class or composition in mixtures should be vaporized. Misting is a thermal process that generates stability in positioning the hair fiber at high temperatures so that they reach a certain dimensional stability ensures that the garment washing and finishing processes will not have problems in their model deformation or shape, improves its subsequent shrinkage and is much more difficult than the fixed tissue present as cracks or folds creasing [9].

Besides the vaporized helps determine the measures before and after dry cleaning to ensure the correct size range.

The steaming process is mandatory for wearing very light fabrics such as Jacquard and flat jersey or requirement and is done on the steam machine purchased with the project which saturated steam blown by the lower table onto 2 systems. Loading the wash program in the PC machine

The computer has a memory machine to insert 50 wash programs according to the material or composition of the garment to be washed, all with a difference of time, temperature, RPM (revolutions per minute). The sequence of steps that are made to load programs into the computer washing Multisolvent Machine are detailed in the manual and machine that requires prior training because technically and specific information that must be entered into the machine (shown in Table I).

\section{E. Verification Process Services and Supplies Washing Machine}

Check that the washing machine has all your supplies and income according to the provisions of the manufacturer.

The machine has the following requirements:

Power supply: The machine requires a supply of 380 volts three phase power $60 \mathrm{Hertz}$. The supply of the machine should be individual from the main incoming line power to the plant, has its protective magnetic thermal $40 \mathrm{amp}$ also has a system ground connection especially well prepared to evacuate electrostatic loads generated the movement of the main drum of the machine.

Air: The air pressure entering the system must not be less than 110 PSI, this is achieved with the use of a compressor 2HP. Connect the compressor, wait to load to 110 PSI then open the appropriate valves to communicate flow and air pressure to the machine.

Water for cooling: Mains water supply to the machine must provide water at a temperature below $20^{\circ} \mathrm{C}$ and at a pressure greater than 40 PSI, which serves to activate all refrigeration systems having the machine in the normal work processes washing and distillation of the solvent.

To this are mounted a $1.5 \mathrm{HP}$ pump with a hydro pneumatic tank 60 liters which together provide the amount of water required for the machine pressure.

The water used by the machine goes at temperatures between 35 and $55^{\circ} \mathrm{C}$ and recovered in the general system of the plant and is used as feed for other laundry processes.

The water supply to the machine is standing while the machine is working.

Nitrogen: The Nitrogen gas supply is elementary, it is required that the machine has a permanent supply of molecular nitrogen gas at a pressure of 75 PSI at the inlet of the machine and not less than 220 bar pressure in the 
dispenser bottle .

This nitrogen is not normally used for the washing process, but it is a system to protect the machine because this when working with solvents and higher temperature conditions exist at $90{ }^{\circ} \mathrm{C}$ in the presence of a normal air atmosphere containing oxygen can lead to an explosion by high low flash point having all solvents for dry cleaning, when the machine through a sensor determines that inside the main drum there these conditions, once the computer sends a signal and opens the inlet valve for spraying nitrogen gas throughout the wash chamber, so the absence of oxygen the chances of an explosion are very slim.

Connexion to Nitrogen gas is permanent while the machine is working.

Important note: If any of the supply does not match the request automatically stops the machine in its operating equipment and giving warning notices in the main panel.

Process load garments.

Taking advantage of the main drum door open we proceed to clean 2 air filters for there is good air circulation inside the machine in the process of drying and cooling, we also clean the filter traps buttons to ensure that no have foreign objects within the system.

Garments or panels are loaded into the machine taking into account that the minimum required by the machine is 3 kilos and the maximum is 12 kilos. When we try to small items can use this up without any problem, but when it comes to very bulk and heavy items should be noted that the load in the machine must have a free rotational movement and fall into the drum of the machine.

The garments are loaded individually so the right side of it, we should try that lots always try to have similar weight or volume.

Items that are loaded must meet the following conditions: Items should be quantified in number of pieces and weight

Samples should be removed by washing each batch to make your key measures such as the main length, width of chest under armhole, sleeve length, skirt width and others as appropriate.

All items must be the same color or combination of colors, we cannot mix light colors with dark colors, garment with accessories of other colors must first be tested to see the effect of the solvent in the migration of dark color to lighter color, must not have large metal fittings and fastenings should be closed.

Garments must be of a single type of fiber, cannot mix different substrates, we must not have different tissue or system design point must be of the same class, we cannot mix light weight clothing fabric clothes heavy fabric.

Not loaded items that are broken.

Once loaded the clothes close the main hatch and pressing the OPEN button closes the whole system. While the machine is working hatches should not be opened.

\section{F. Washing Process}

This description is based on the final tests in the process of determining the best solvent to wash clothes Alpaca fiber. Once loaded the garments (Table I) program that we have developed for type washing we want to do is run.

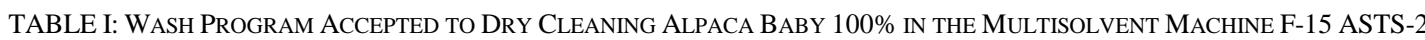

\begin{tabular}{|c|c|c|c|c|c|c|c|c|}
\hline \multicolumn{9}{|c|}{ SOLVENT DF 2000} \\
\hline \multicolumn{2}{|r|}{ FIBER TYPE } & \multicolumn{7}{|c|}{ Baby alpaca $100 \%$ and mixes } \\
\hline \multirow[b]{3}{*}{$\begin{array}{l}\mathbf{N}^{\circ} \\
\text { STEP }\end{array}$} & & \multicolumn{7}{|c|}{ Jersey, Link, others } \\
\hline & \multirow[b]{2}{*}{ ACTIVITY } & \multirow[b]{2}{*}{ FUNCTIONS } & \multicolumn{2}{|c|}{ TIME } & \multirow{2}{*}{$\begin{array}{l}\text { WASH } \\
\text { RPM }\end{array}$} & \multicolumn{3}{|c|}{ TEMPERATURE ${ }^{\circ} \mathrm{C}$} \\
\hline & & & SECONDS & MINUTES & & \begin{tabular}{|l} 
INCOME \\
DRUM
\end{tabular} & COOLING & $\begin{array}{c}\text { OUTPUT } \\
\text { DRUM }\end{array}$ \\
\hline 1 & Turn on to destiller & 25 & 4 & & & & & \\
\hline 2 & $\begin{array}{l}\text { Solvent go from to first deposit to the } \\
\text { pump and discharge water from dryer } \\
\text { separator. }\end{array}$ & 1-12-22-28-42 & & & & & & \\
\hline 3 & $\begin{array}{l}\text { Washing pipe separator drum drying } \\
\text { solvent }\end{array}$ & $1-12-28-39-50$ & 30 & & 40 & & & \\
\hline 4 & Send solvent to main drum & 1-12-15-28 & 30 & & & & & \\
\hline 5 & Normal pre-washing & 1-15-16-21-28 & & 3 & 40 & & & \\
\hline 6 & Send solvent from main drum to destiller & 21-25-28 & 20 & & & & & \\
\hline 7 & $\begin{array}{l}\text { Slow spin and discharge of solvent to } \\
\text { destiller }\end{array}$ & 3-21-25-28 & & 1 & & & & \\
\hline 8 & Send solvent from deposit 1 to main drum & $12-15-28$ & 30 & & & & & \\
\hline 9 & Delicate wash & 2-15-16-21-28 & & 3 & 40 & & & \\
\hline 10 & Send solvent to deposit 1 & 2-21-22-28 & 40 & & & & & \\
\hline 11 & $\begin{array}{l}\text { Slow spin and discharge of solvent to } \\
\text { deposit } 1\end{array}$ & 3-21-22-28 & & 2 & & & & \\
\hline 12 & Hard spin and star drying & 3-8-21-22-28 & & 4 & & & & \\
\hline 13 & $\begin{array}{l}\text { Pre-dry, odor removal and cooling of } \\
\text { solvent }\end{array}$ & $2-6-7-8$ & & 10 & & 75 & 35 & 65 \\
\hline 14 & $\begin{array}{l}\text { Dry, odors removal, cooling with a Dry } \\
\text { Control system }\end{array}$ & 2-6-7-8-9 & & 30 & & 75 & 35 & 65 \\
\hline 15 & $\begin{array}{l}\begin{array}{l}\text { Post-dry, odors removal and cooling of } \\
\text { solvent }\end{array} \\
\end{array}$ & 2-6-7-8 & & 3 & & 75 & 35 & 65 \\
\hline 16 & Cooling of garments and machine & 2-6-7 & & 5 & & & & \\
\hline 17 & Registration of steps & 2-6-7-11 & 2 & & & & & \\
\hline
\end{tabular}


The dosage of the washing solvent is: 3 kilos of solvent per kilo of garments.

Threads that are made in the process of washing through the program in the computer of the machine are:

- Circular Movement in both directions and times of rest of the clothes inside the drum major.

- washing of the garments with the amount of solvent that enters the drum through the program that activates the opening of the inlet valve to the main cylinder and the main pump to remove the solvent from the solvent tank 1. In some cases it is possible to use the remaining solvent from one of the separators of the machine.

- Circulation of the solvent through the main drum to boost washing.

- In the cleaning process the solvent removes all stains, grease, oil and dirt from the clothes and the scavenged to keep dispersed in the solvent and then separating them in the distillation process.

- How filters fluid to clean the solvent.

- Operation of the water pump to activate all the cooling systems of the machine.

- Operation and heating distiller for the process of evaporation and condensation of the solvent.

- The wash times are determined in the wash.

\section{Spin process and solvent extraction:}

Upon completion of the washing, the solvent containing any contaminants must be removed from the clothes and to be sent to distillation unit for cleaning.

For this, the machine enters the spin system which is based on the centrifugal force that makes all the solvent out through the holes in the main drum and using the main pump is sent to the distillation.

The distiller allow evaporation of solvent to $174{ }^{\circ} \mathrm{C}$, temperature difference of boiling of the other components and performs a process of purification, the solvent evaporated leaving the top of the evaporator and passes through a manifold which has an internal cooling system makes solvent vapors condense and be sent to the standoffs .

The machine has three separators, in the lower water separator that separates from the solvent in the distiller, at a middle divider collects the condensed solvent is accumulated as the part that comes first distiller and upper separator accumulates solvent that comes as part of the second evaporator.

The solvent of the upper 2 dividers can be sent to the main tank of solvent through the program or manually to be used for other washing processes.

Any remaining, dirt, grease and dirt get inside the distiller and clean them with a weekly or monthly basis depending on the number of washes that are made.

\section{G. Drying and Deodorizing}

The garments are derived squeezed dry to remove all solvent and the same manner as in the above process the solvent is sent to the distillation.

For this process the machine while the articles are still moving into the main drum, this raises the temperature in the main cylinder up to $75^{\circ} \mathrm{C}$ at which temperature all the solvent is removed from the garments thereby ensuring that no logout washing machine .

The machine has a drying sensor that controls all the time the amount of solvent is in the clothes, when the system checks that there is no solvent in the garments this sensor causes the program advances to the next step thus ending the process drying.

While the drying process takes the odor extraction process, which is a suction system through a fan to ensure that clothes besides not having solvent having no solvent odor DF 2000 is also activated.

Once the drying process and deodorized, the system must be cooled to below $28^{\circ} \mathrm{C}$ to enable the garments can be extracted from the machine through the main hatch.

The spots that remain after this process have very little chance that can be removed, but if the fabric normally allows a new manual spotting and a second cleaning is attempted. For our case the clothes washing newly -woven panels and you feel that this is not applicable.

\section{H. Final Inspection Process}

The washed clothes and undergo a quality inspection process to assess the performance and efficiency of the washing process.

The parameters evaluated within the Cleaning mill are:

- Smoothness: It is a test that aims to assess the softness, shine and fall of the garment, this is done manually and the rating is subjective according to textile expert. The procedure is to benchmark with a standard sample of known characteristics and approved with high values.

Evaluated the amount of clothes is only a percentage of the total and can be determined through an inspection AQL table level is suggested to use general inspection level $1 \mathrm{~B}$ factor 25 to determine acceptance or rejection of the lot .

This parameter is negotiating high value on quality of the garment if it is mainly Alpaca.

If items do not meet the respective approval should be evaluated for a rework.

- Degree of cleaning: This quality parameter measures the degree of brightness and hue must possess the garment as well as the absence of spots or stains of any kind. Verification is purely visual, the clothes are reviewed at $100 \%$, and the clothes that do not pass this test must pass a rework.

- Textile garment odor: The odor evaluation textile is also a subjective value and is through smell that can be identified in the garment. Items should have a very soft fabric sexy scent that is not related to normal solvent odors. For this test the use of general inspection level 1B factor 25 is also suggested for rejection or approval.

- Dimensional stability after washing: Garments after washing should be measured to know how much shrinkage after washing. These measures should be compared against shots upstream measures and as soon as we get the difference is the residual shrinkage to dry cleaning with DF 2000, the method applied is based on the standard AATCC 158-2011 dimensional changes on laundering dry. As this is Alpaca garments are not possible AQL evaluation systems because of the cost involved, it is sufficient for us to wash and dry one garment for each model knowing that you can have several lots, we found that the difference between the results of 
shrinkage is almost close to zero.

- Not considered doing testing dimensional stability of the domestic washing water with the AATCC 150, because in Alpaca garments should be compulsorily inserted label recommendations for use and washing and they must clearly show that the garment should be washed only dry.

\section{Steaming Process 2}

To give the final appearance of the garments should vaporize back into the vaporized table This steaming process ensures that the items are in the correct final measures committed to the customer and must be done manually by a trained person using a flex meter and table specifications of the garment.

\section{J. Quality Control}

Alpaca garments are very valuable to us and to the market, so we must ensure that these maintain a high level of quality that meets the expectations of the National and International market. For this we must necessarily textile testing to ensure these results. [10].

The quality control tests to be done through a certifying laboratory are:

- Test and level of pilling appearance ASTM D 3512

- Light fastness xenon AATCC 16-2004

- Dimensional changes to dry cleaning AATCC 158 2011

- Appearance after dry cleaning: visual color change evaluation

For this we can make use of the services of the following Peruvian Certifying Laboratories:

- Quality Lab SAC

- SAC Certintex

- SGS from Perú

\section{K. Results Achieved and Validated}

Quality tests conducted to garments washed with DF 2000 underwent a Certification Laboratory institution validated passing results for each test which can guarantee the quality of the wash or cleaning.

\section{CONCLUSION}

According to the evaluation and analysis of results, we conclude that the washing with solvent DF 2000 is described in this report, we ensure good performance and repeatability of a good process of dry cleaning Clothes Alpaca fiber and mixtures in Arequipa City, as an alternative to the replacement of traditional washing with solvent perchlorethylene.

The results of the tests of quality (level of pilling, cleanliness, textile odor, dimensional stability, light fastness) show that clothes washed with the solvent DF 2000 with excellent performance, which have been ratified by the results of tests conducted by Quality Lab SAC.

We also found that the levels of quality of clothes washed with the solvent DF 2000 we are above current market levels by employing the traditional dry cleaning using perchlorethylene solvent.

The international market mainly prefers organic products and processes which generate a high probability consolidate this business.

\section{ACKNOWLEDGMENT}

The author thanks all members of the technical team that worked on this project. Also in support of the Peruvian government through the Fincyt, Reactivos Jeans SRL Company, San Pablo Catholic University of Perú and The Energy Environmental Institute they all made it possible to achieve these results. This work was supported by the Peruvian Government FINCYT-FIDECOM (Ministery of Production).

\section{REFERENCES}

[1] Beyond scarcity: Power, poverty and the global water crisis, Human Development Report, UNDP, 2006, Combat water shortage, The challenge of the XXI Century, UN-Water, FAO. 20 -2006, Chemicals Used In Drycleaning Operations pp. 4, January, 2002.

[2] R. E. Doherty, "A History of the production and use of carbon tetrachloride, tetrachloroethylene, trichloroethylene and 1,1,1-trichlroethane in the united states," Part 1 in Historical Background; Carbon Tetrachloride and Tetrachloroethylene, Environmental Forensics, pp. 69-81, 2000.

[3] Sciences International, Inc. Toxicological Profile for Stoddard Solvent. Washington D.C.: U.S, Department of Health and Human Services Public Health Service, Agency for Toxic Substances and Disease Registry, 1995.

[4] United States Environmental Protection Agency, National Perchloroethylene Air Emission Standards for Dry Cleaning Facilities: Final Rule Part II, Washington D.C.: U.S. E.P.A. Federal Register, 40 CFR, vol. 63, July 2006.

[5] California Air Resources Board (CARB), Dry Cleaning Alternative Solvents: Health and Environmental Impacts, Sacramento: California Air Resources Board Fact Sheet, March 2008.

[6] DF-2000 FLUID, Material safety data sheet MSDS DF 2000, pp. 1-11, Exxon Mobile USA 2011.

[7] Firbimatic spa S.U.via Turati 1640010 Sala Bolognese - Bologna Italy. [Online]. Available: http://www.firbimatic.itFirbimatic

[8] Technological aspects of Andean camelid fiber (1991) production of small ruminants, Alpacas, Program to support collaborative research in small ruminants, Carpio, Manuel, 2001.

[9] M. Costa, Fibers and Textiles Dyeing, Perú, 2007.

[10] Report of expert committee, AATCC, vol. 1, 2005.

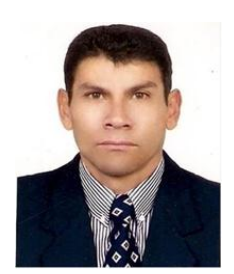

Zegarra A. was born on July 9, 1961. He got his master degree in operations. He is a chemical engineer project engineer, and textile expert with over 20 years experience in industry and textiles processes, mainly cotton, Alpaca wool and mixtures thereof. He is a expert in systems treating effluents from the textile industry. Currently he works as a teacher in the San Pablo Catholic University of Arequipa in the Industrial Engineering courses in the chemical industry. The author is a process consultant textiles and management systems who has been repeatedly invited as a speaker at universities in the region and the College of Engineers of Perú. Besides he is the manager of Reactivos Jeans SRL small business the textile industry - Laundry and Dry-cleaning in Arequipa City and is part of the team as a textile expert in project development PIPEA 091- 2011 and associated to the CONCYTEC researcher in Perú. 